Article

\title{
Free Vibration Analysis of Functionally Graded Porous Doubly-Curved Shells Based on the First-Order Shear Deformation Theory
}

\author{
Farajollah Zare Jouneghani ${ }^{1} \mathbb{C}^{\mathbb{B}}$, Rossana Dimitri ${ }^{2}$, Michele Bacciocchi ${ }^{3}$ (D) and \\ Francesco Tornabene ${ }^{3, *}$ \\ 1 Young Researchers and Elite Club, Shahrekord Branch, Islamic Azad University, Shahrekord, Iran; \\ f.zarejouneghani@gmail.com \\ 2 Department of Innovation Engineering, School of Engineering, University of Salento, 73100 Lecce, Italy; \\ rossana.dimitri@unisalento.it \\ 3 DICAM-Department, School of Engineering and Architecture, University of Bologna, 40136 Bologna, Italy; \\ michele.bacciocchi@unibo.it \\ * Correspondence: francesco.tornabene@unibo.it; Tel.: +39-051-209-3500
}

Received: 28 October 2017; Accepted: 29 November 2017; Published: 2 December 2017

\begin{abstract}
Due to some technical issues that can appear during the manufacturing process of Functionally Graded Materials (FGMs), it can be extremely difficult to produce perfect materials. Indeed, one of the biggest problems is the presence of porosities. For this purpose, the vibrational behavior of doubly-curved shells made of FGM including porosities is investigated in this paper. With respect to previous research, the porosity has been added to the mechanical model that characterizes the through-the-thickness distribution of the graded constituents and applied to doubly-curved shell structures. Few papers have been published on this topic. In fact, it is easier to find works related to one-dimensional structures and beam models that take account the effect of porosities. The First-order Shear Deformation Theory (FSDT) is considered as the theoretical framework. In addition, the mechanical properties of the constituents vary along the thickness direction. For this purpose, two power-law distributions are employed to characterize their volume fraction. Strain components are established in an orthogonal curvilinear coordinate system and the governing equations are derived according to the Hamilton's principle. Finally, Navier's solution method is used and the numerical results concerning three different types of shell structures are presented.
\end{abstract}

Keywords: functionally graded materials; porosity; doubly-curved shells; vibrations; first-order shear deformation theory

\section{Introduction}

Functionally Graded Materials (FGMs) are well-known composite materials whose properties change smoothly along one or multiple directions. FGMs were studied for the first time by Niino et al. [1] in 1984 for aerospace applications, and have been increasingly adopted in the literature as multi-function materials for different engineering applications. These materials are produced by blending two materials such as metals and ceramics together, and are able to eliminate stress discontinuities commonly present in layered composites. Thus far, different studies have focused on the mechanical behavior of FGMs. Wattanasakulpong and Chaikittiratana [2], for example, proposed an analytical study for the free vibration of doubly-curved Functionally Graded (FG) shallow shells with stiffeners, under a thermal environment. Tornabene et al. [3] investigated the free vibration of free-form doubly-curved FG shells. In two papers, Kiani et al. [4,5] investigated the static and dynamic behavior of a FGM doubly-curved panel. Sayyadi and Farsangi [6] also presented an analytical solution for the free vibration and dynamic problem of thick doubly-curved FG smart panels. 
Porosities and micro-voids are common technical issues that may be introduced during the manufacturing process, with a consecutive reduction of their mechanical properties [7]. This possible relationship between porosity and mechanical properties of materials has increased the interest of the scientific community in obtaining more precise results both experimentally and theoretically. Wang et al. [7] investigated the vibration behavior of FG porous rectangular plates in a thermal environment. Shafiei and Kazemi [8,9] studied the buckling behavior of FG tapered and simple beams made by porous materials, and verified that an increasing porosity volume fraction yields to a decrease in stiffness and buckling load. A general nonlocal approach based on the strain-gradient elasticity model was developed by Shahverdi and Reza Barati [10] for the vibration analysis of porous nano plates resting on elastic substrates.

Many applications of single- or doubly-curved shells have increased the scientific attention to the mechanical behavior of these useful structural components. Several studies on doubly-curved shells are available in the literature. A brief review is presented here for the sake of completeness. Tornabene [11] and Tornabene et al. [12,13] investigated the free vibrations of anisotropic doubly-curved shells of revolution defined by free-form meridians. Viola et al. [14] and Tornabene et al. [15,16] employed a higher-order formulation, based on an equivalent single layer approach, for the mechanical analysis of laminated composite shell structures characterized by curved surfaces as reference domains. A layer-wise formulation was presented instead in the paper by Tornabene et al. [17] for the same purpose. A Moving Least Squares Differential Quadrature (MLSDQ) method based on Radial Basis Functions (RBFs) was developed by Tornabene et al. [18] to perform the free vibration analysis of laminated composite doubly-curved shells. The weak form of the governing equations of doubly-curved shells was solved by Tornabene et al. [19] to obtain the natural frequencies of shell structures characterized by distorted domains. For this purpose, an approach based on Non Uniform Rational Basis-Splines (NURBS) was developed. Tornabene et al. [20] employed a local version of the Generalized Quadrature Method (GDQ) for the dynamic analysis of FGM sandwich shells with variable thickness. The topic of shell structures with variable thickness was studied also by Amabili [21], who proposed a nonlinear higher-order shear deformation theory. A third-order shear deformation theory was developed by Amabili $[22,23]$ to investigate the nonlinear mechanical behavior of both isotropic and laminated doubly-curved shells. Amabili [24] and Amabili and Reddy [25] included the stretching effect and shear strains in their higher-order formulation for the large-amplitude vibrations of laminated doubly curved shells. Tornabene et al. [3] analyzed the free vibration of free-form doubly-curved shells made by FGMs, while applying some higher-order theories. Tornabene et al. [26] investigated the agglomeration effect on the natural frequency of FG carbon nano-tube-reinforced laminated composite doubly-curved shells. A further study on nonlinear vibrations of doubly-curved shallow shells can be found in Amabili [27]. Fadaee et al. [28] investigated the free vibrations of FG spherical shell panel using an innovative exact closed-form solution. A higher-order facet shell element was developed by Khare et al. [29] for the free vibration analysis of composite and sandwich laminates.

Few studies conducted thus far, however, have focused on the mechanical behavior of doubly-curved shells made by FGM in the presence of porosities. This problem is tackled here numerically, while focusing on the free vibration of FG porous doubly-curved shell with simply supported boundary conditions. This is the main novel aspect introduced in the paper, since previous works were focused only on beam structures and one-dimensional models. An improved third-order shear deformation theory was employed by Wattanasakulpong et al. [30] to formulate the governing equations for the free vibrations of functionally graded beams including porosities. The same analyses were performed by Wattanasakulpong and Ungbhakorn [31], including the effect of nonlinearities on the structural response. In their paper, the influence of porosities on the structural response was proven through a set of experimental analyses. Wattanasakulpong and Chaikittiratana [32] studied the flexural vibration of functionally graded beams based on Timoshenko theory by means of the Chebyshev collocation method. The Timoshenko beam theory was employed by Shafiei et al. [33] to investigate the vibrational behavior of two-dimensional functionally graded nano and microbeams including 
porosities. To this aim, the Eringen's nonlocal elasticity and the modified couple stress theories were employed. Ebrahimi and Zia [34] investigated the large-amplitude nonlinear vibration characteristics of functionally graded Timoshenko beams made of porous constituents. Finally, Fazzolari investigated the vibration and stability analyses of porous FG sandwich beams resting on elastic foundations [35]. For this purpose, various hierarchical refined exponential, polynomial, and trigonometric higher-order beam theories were developed in a generalized manner. An empirical approach has been used in all the aforementioned papers concerning porous and imperfect media to evaluate the overall mechanical properties of the composites at issue [30-35]. For this purpose, the well-known rule of mixture has been modified to deal with porosities. Since this approach has been validated by other authors, as illustrated in [30-35], the same empirical scheme is employed in the present paper to deal with FGM structures. The methodology in hand is also extended to the case of shell structures, since the previous studies are mainly focused on beams and plates with porosities. In other words, the authors do not aim to propose a new micromechanical scheme for porous and imperfect media, but their purpose is to apply an existing homogenization technique, the rule of mixture, to easily include and investigate the presence of porosities in a functionally graded material.

The First-order Shear Deformation Theory (FSDT), combined with the Hamilton's principle, is applied to obtain the governing equations of the problem [36-39], which is defined by means of five dynamic parameters. The accuracy of the proposed formulation is thus verified through a comparative evaluation between our results and some predictions available in the literature.

The remainder of this paper is organized as follows: the geometry problem is first reviewed and detailed for doubly-curved shells in Section 2. Section 3 is concerned with a further review of FGMs, which are applied in Section 4 within the proposed mathematical formulation. The numerical solution of the problem is detailed in Section 5, while discussing about the numerical results and their comparative evaluation with predictions from the literature in Section 6. Finally, conclusions are drawn in Section 7.

\section{Brief Review of the Curvilinear Coordinate System}

Figure 1 illustrates a doubly-curved shell with thickness $h$, defined in a curvilinear orthogonal coordinate system $\left(\alpha_{1}, \alpha_{2}, \zeta\right)$, where $\alpha_{1}$ and $\alpha_{2}$ refer to the principal lines of curvature on the neutral surface $(\zeta=0)$, whereas $\zeta$ is perpendicular to the neutral surface itself. In addition, $R_{1}$ and $R_{2}$ are the curvature radii along $\alpha_{1}$ and $\alpha_{2}$ directions, respectively.

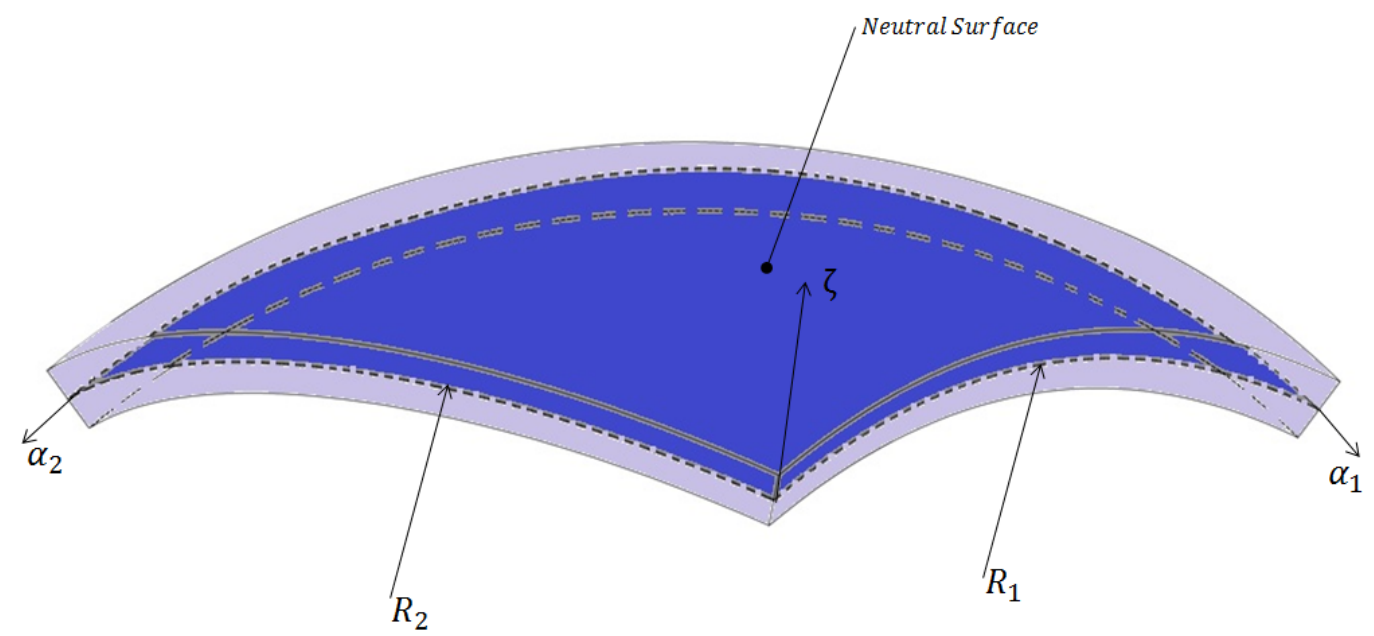

Figure 1. Geometry of doubly-curved shell and its coordinate systems. 
By considering a generic point $\mathrm{P}$ on the neutral surface, its location is defined through the position vector $r$ :

$$
r=f_{1}\left(\alpha_{1}, \alpha_{2}\right) e_{1}+f_{2}\left(\alpha_{1}, \alpha_{2}\right) e_{2}+f_{3}\left(\alpha_{1}, \alpha_{2}\right) e_{3},
$$

where $e_{1}, e_{2}, e_{3}$ are the unit vectors standing for the principal directions in a three-dimensional setting. Meanwhile, $f_{1}, f_{2}, f_{3}$ are smooth functions that characterize the parametric surface.

The distance between point $P$ and a reference point in orthogonal curvilinear coordinates is given by:

$$
(d s)^{2}=A_{1}^{2}\left(d \alpha_{1}\right)^{2}+A_{2}^{2}\left(d \alpha_{2}\right)^{2},
$$

where $d s$ stands for the infinitesimal curvilinear length that can be measured between $\mathrm{P}$ and the reference point at issue, within the shell middle surface. The symbols $A_{1}$ and $A_{2}$ are the Lamé parameters defined by

$$
\left\{\begin{array}{l}
A_{1}^{2}=\frac{d r}{d \alpha_{1}} \cdot \frac{d r}{d \alpha_{1}} \\
A_{2}^{2}=\frac{d r}{d \alpha_{2}} \cdot \frac{d r}{d \alpha_{2}}
\end{array} .\right.
$$

The distance $d S$ between two close points within the three-dimensional shell element in orthogonal curvilinear coordinates can be deducted through the following compact expression

$$
(d S)^{2}=\sum_{i=1}^{3} g_{i i}\left(\alpha_{1}, \alpha_{2}, \zeta\right)\left(d \alpha_{\mathrm{i}}\right)^{2},
$$

where

$$
\begin{gathered}
g_{11}=A_{1}^{2}\left(1+\frac{\zeta}{R_{1}}\right)^{2} \\
g_{22}=A_{2}^{2}\left(1+\frac{\zeta}{R_{2}}\right)^{2} \\
g_{33}=1 .
\end{gathered}
$$

It should be recalled that the Lamé parameters $A_{1}, A_{2}$ and the two curvature radii $R_{1}, R_{2}$ must fulfill the Gauss-Codazzi conditions shown below:

$$
\begin{gathered}
\frac{1}{R_{2}} \frac{\partial A_{1}}{\partial \alpha_{2}}=\frac{\partial}{\partial \alpha_{1}}\left(\frac{A_{1}}{R_{1}}\right) \\
\frac{1}{R_{1}} \frac{\partial A_{2}}{\partial \alpha_{1}}=\frac{\partial}{\partial \alpha_{2}}\left(\frac{A_{2}}{R_{1}}\right) \\
\frac{\partial}{\partial \alpha_{1}}\left(\frac{1}{A_{1}} \frac{\partial A_{2}}{\partial \alpha_{1}}\right)+\frac{\partial}{\partial \alpha_{2}}\left(\frac{1}{A_{2}} \frac{\partial A_{1}}{\partial \alpha_{2}}\right)=-\frac{A_{1} A_{2}}{R_{1} R_{2}} .
\end{gathered}
$$

Further details concerning the analytical description of doubly-curved surfaces can be found in the book by Tornabene and Fantuzzi [38].

\section{Functionally Graded Materials}

The material considered in this study is a combined metal and ceramic, whose volume fractions are assumed to be variable along the $\zeta$-direction. In a context where even or uneven distributions of porosity are commonly assumed in the literature, the present work considers an even distribution of porosity, equally distributed within the material.

The Young's Modulus E, the Poisson's ratio $v$, and the density of the shell $\rho$, are assumed to vary through the thickness according to a power law distribution and even porous distribution, as defined in the following:

$$
\begin{gathered}
E(\zeta)=\left[E_{c}-E_{m}\right] V_{c}+E_{m}-\frac{\beta}{2}\left[E_{c}-E_{m}\right] \\
v(\zeta)=\left[v_{c}-v_{m}\right] V_{c}+v_{m}-\frac{\beta}{2}\left[v_{c}-v_{m}\right] \\
\rho(\zeta)=\left[\rho_{c}-\rho_{m}\right] V_{c}+\rho_{m}-\frac{\beta}{2}\left[\rho_{c}-\rho_{m}\right],
\end{gathered}
$$


where the subscripts $m$ and $c$ refer to the metal and ceramic, respectively, $\beta$ (with $\beta \ll 1$ ) is the porosity volume fraction, and $V_{c}$ and $V_{m}$ refer to the volume fraction of the ceramic and metal, respectively. As can be noted from Equations (9)-(11), the overall mechanical properties of the composite are computed through the well-known rule of mixture, which has been properly modified to take into account the porosity of the medium [31]. The same empirical approach has been recently employed and validated by many authors to describe the porous phase of FGMs [30-35]. To the best of the authors' knowledge, the rule of mixture represents a simple homogenization technique that allows us to evaluate in an efficient manner the elastic properties of a graded composite. Nevertheless, it can be recalled that more refined approaches are available in the literature, as highlighted in the paper by Tornabene et al. [39]. For instance, the Mori-Tanaka scheme could be used as an alternative to the theory of mixture, as illustrated in [3], where the classic theory of mixtures is compared to the more refined scheme. Nevertheless, the numerical analyses shown in the paper by Tornabene et al. [3] proved that similar results can be obtained by using these two micromechanical approaches. Thus, a proper set of experimental analyses should be performed to understand which is the best methodology for evaluating the mechanical properties of porous FGMs. Nevertheless, the Mori-Tanaka scheme could provide a better physical interpretation of the mechanical behavior of FGMs [3]. As specified in the introduction, the paper does not aim to discuss the micromechanics of porous media, but is focused on the effect that porosities could have on the structural response of FGM shells by using existing approaches.

Based on the rule of mixture, the following relation can be deduced:

$$
V_{m}+V_{c}=1
$$

In this study, the volume fraction of ceramic $V_{c}$ is modeled according to the following power-law distributions, namely

$$
\begin{aligned}
& \text { FGM - type } 1: V_{c}=\left(\frac{2 \zeta+h}{2 h}\right)^{p} \\
& \text { FGM - type } 2: V_{c}=\left(\frac{2 \zeta-h}{2 h}\right)^{p},
\end{aligned}
$$

where $p \in[0, \infty)$ is the FG power-law index. Figure 2 illustrates the variation of the ceramic volume fraction vs. the dimensionless thickness coordinates for different values of $p$.
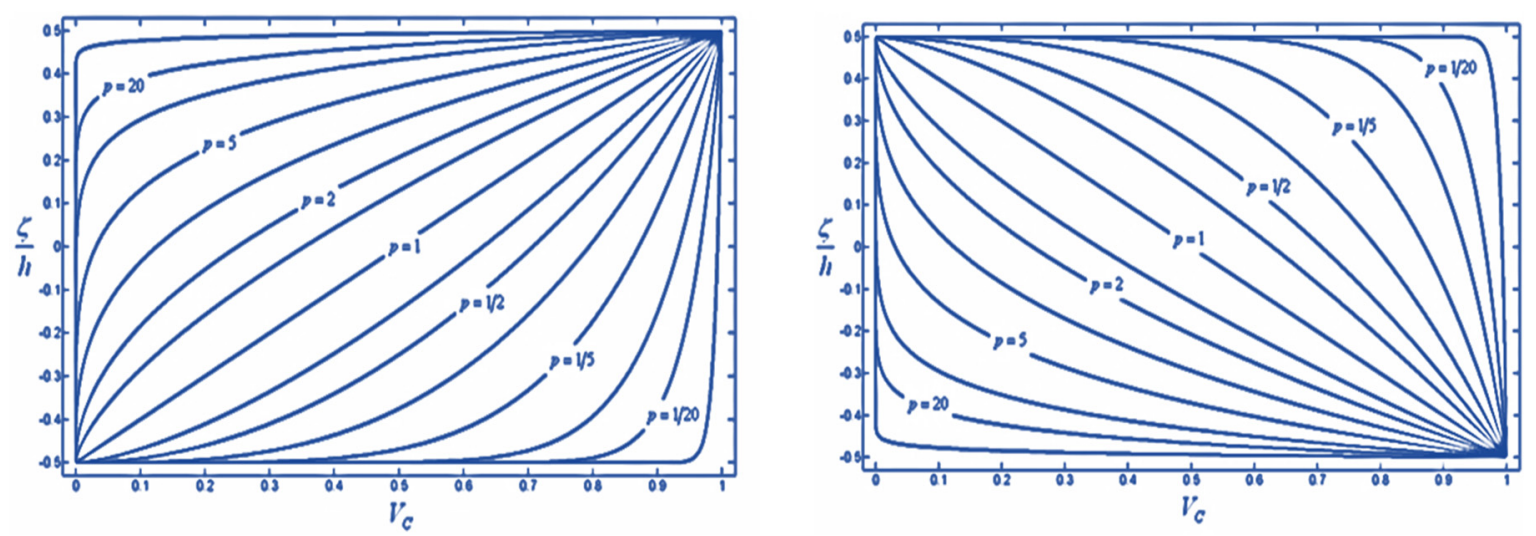

Figure 2. Different volume fraction of ceramic along the thickness for different values of power-law index: (a) FGM (Functionally Graded Material)-type 2; (b) FGM-type 1 [38]. 


\section{Mathematical Modeling}

According to the First-order Shear Deformation Theory (FSDT), the three-dimensional displacements $\left(u_{1}, u_{2}, u_{3}\right)$ are defined as follows [13,38]:

$$
\begin{gathered}
u_{1}=u+\zeta \beta_{1} \\
u_{2}=v+\zeta \beta_{2} \\
u_{3}=w
\end{gathered}
$$

where $u, v$, and $w$ are the displacement components, and $\beta_{1}$ and $\beta_{2}$ are the rotations of the tangents to the middle surface about $\alpha_{1}$ and $\alpha_{2}$ axes, respectively. These five parameters are the degrees of freedom of the problem and can be collected in the corresponding vector $U$.

The equations of motion can be derived through the Hamilton's variational principle, applied within a generic time interval bounded by $t_{0}, t_{1}$ :

$$
\int_{t_{0}}^{t_{1}}(\delta U+\delta W-\delta K) d t=0
$$

where $\delta U, \delta K$, and $\delta W$ are the variations of strain energy and kinetic energy, as well as the work done by the external forces, respectively. The strain energy of an elastic body occupying a volume $V$ is defined as follows:

$$
U=\frac{1}{2} \int\left(\sigma_{i j} \varepsilon_{i j}\right) d V .
$$

The three-dimensional strain components are defined as

$$
\begin{gathered}
\varepsilon_{11}=e_{11}+\zeta k_{11} \\
\varepsilon_{22}=e_{22}+\zeta k_{22} \\
\varepsilon_{12}=\frac{1}{2}\left[e_{12}+\zeta k_{12}\right] \\
\gamma_{13}=\beta_{1}+\frac{\partial w}{\partial \alpha_{1}}-\frac{u}{R_{1}} \\
\gamma_{23}=\beta_{2}+\frac{\partial w}{\partial \alpha_{2}}-\frac{v}{R_{2}},
\end{gathered}
$$

where

$$
\begin{gathered}
e_{11}=\frac{1}{\left(1+\zeta / R_{1}\right)}\left[\frac{\partial u}{\partial \alpha_{1}}+\frac{w}{R_{1}}\right] \\
e_{22}=\frac{1}{\left(1+\zeta / R_{2}\right)}\left[\frac{\partial v}{\partial \alpha_{2}}+\frac{w}{R_{2}}\right] \\
e_{12}=\frac{1}{\left(1+\zeta / R_{2}\right)}\left[\frac{\partial u}{\partial \alpha_{2}}\right]+\frac{1}{\left(1+\zeta / R_{1}\right)}\left[\frac{\partial v}{\partial \alpha_{1}}\right] \\
k_{11}=\frac{1}{\left(1+\zeta / R_{1}\right)}\left[\frac{\partial \beta_{1}}{\partial \alpha_{1}}\right] \\
k_{22}=\frac{1}{\left(1+\zeta / R_{2}\right)}\left[\frac{\partial \beta_{2}}{\partial \alpha_{2}}\right] \\
k_{12}=\frac{1}{\left(1+\zeta / R_{2}\right)}\left[\frac{\partial \beta_{1}}{\partial \alpha_{2}}\right]+\frac{1}{\left(1+\zeta / R_{1}\right)}\left[\frac{\partial \beta_{2}}{\partial \alpha_{1}}\right],
\end{gathered}
$$

under the assumption $A_{1}=A_{2}=1$, related to the correspondence between curvilinear abscissae and principal coordinates. 
The stress-strain relationships at a given point within the FGM porous doubly-curved shell element take the following form:

$$
\left\{\begin{array}{l}
\sigma_{11} \\
\sigma_{22} \\
\sigma_{12} \\
\sigma_{23} \\
\sigma_{13}
\end{array}\right\}=\left[\begin{array}{ccccc}
C_{11} & C_{12} & 0 & 0 & 0 \\
C_{12} & C_{22} & 0 & 0 & 0 \\
0 & 0 & C_{66} & 0 & 0 \\
0 & 0 & 0 & C_{44} & 0 \\
0 & 0 & 0 & 0 & C_{55}
\end{array}\right]\left\{\begin{array}{c}
\varepsilon_{11} \\
\varepsilon_{22} \\
\gamma_{12} \\
\gamma_{23} \\
\gamma_{13}
\end{array}\right\},
$$

where the three-dimensional stress components are indicated on the left. Here, $C_{i j}$ are the elastic coefficients included in the corresponding elasticity matrix. They are defined below as

$$
C_{11}=\frac{E(\zeta)}{1-v(\zeta)^{2}}, C_{12}=v(\zeta) C_{11}, C_{22}=C_{11}, C_{44}=C_{55}=C_{66}=\frac{E(\zeta)}{2(1+v(\zeta))}
$$

The kinetic energy $K$ can be written as follows:

$$
K=\frac{1}{2} \int_{V} \rho(\zeta) \dot{U}^{T} \dot{U} d V
$$

where $U$ is the displacement vector, which collects the three-dimensional displacement components introduced above. The dot notation used in the expression above stands for the time derivative. In other words, $\dot{U}$ collects the velocity components. On the contrary, the variations of the work done by external forces is given by

$$
\delta W=\int_{\alpha_{2}} \int_{\alpha_{1}}\left(q_{1} \delta u+q_{2} \delta v+q_{3} \delta w\right) d \alpha_{1} d \alpha_{2}
$$

where $q_{1}, q_{2}$, and $q_{3}$ are the external forces along the $\alpha_{1}, \alpha_{2}$, and $\zeta$ directions, respectively. By combining all the energy variations, substituting them into Equation (19), and finally gathering the virtual displacement $\delta u, \delta v, \delta w, \delta \beta_{1}$, and $\delta \beta_{2}$, the five governing equations are expressed as in the following:

$$
\begin{gathered}
\delta u: \frac{\partial N_{11}^{\sigma}}{\partial \alpha_{1}}+\frac{\partial N_{21}^{\sigma}}{\partial \alpha_{2}}+\frac{Q_{13}^{\sigma}}{R_{1}}+q_{1}=I_{0} \ddot{u}+I_{1} \ddot{\beta}_{1} \\
\delta v: \frac{\partial N_{12}^{\sigma}}{\partial \alpha_{1}}+\frac{\partial N_{22}^{\sigma}}{\partial \alpha_{2}}+\frac{Q_{23}^{\sigma}}{R_{2}}+q_{2}=I_{0} \ddot{v}+I_{1} \ddot{\beta}_{2} \\
\delta w: \frac{\partial Q_{13}^{\sigma}}{\partial \alpha_{1}}+\frac{\partial Q_{23}^{\sigma}}{\partial \alpha_{2}}-\frac{N_{11}^{\sigma}}{R_{1}}-\frac{N_{22}^{\sigma}}{R_{2}}+q_{3}=I_{0} \ddot{w} \\
\delta \beta_{1}: \frac{\partial M_{11}^{\sigma}}{\partial \alpha_{1}}+\frac{\partial M_{12}^{\sigma}}{\partial \alpha_{2}}-Q_{13}^{\sigma}=I_{1} \ddot{u}+I_{2} \ddot{\beta}_{1} \\
\delta \beta_{2}: \frac{\partial M_{21}^{\sigma}}{\partial \alpha_{1}}+\frac{\partial M_{22}^{\sigma}}{\partial \alpha_{2}}-Q_{23}^{\sigma}=I_{1} \ddot{v}+I_{2} \ddot{\beta}_{2},
\end{gathered}
$$

where $I_{0}, I_{1}$ and $I_{2}$ being the normal, coupled normal-rotary and rotary inertia coefficients, respectively, which are defined below:

$$
I_{i}=\int_{-\frac{h}{2}}^{\frac{h}{2}} \rho(\zeta) \zeta^{i}\left(1+\frac{\zeta}{R_{1}}\right)\left(1+\frac{\zeta}{R_{2}}\right) d \zeta i=0,1,2
$$


It should be noted that the stress results must be introduced, too. More specifically, $N_{11}^{\sigma}, N_{12}^{\sigma}, N_{22}^{\sigma}$, and $N_{21}^{\sigma}$ are the in-plane stress resultants, $Q_{13}^{\sigma}$ and $Q_{23}^{\sigma}$ are the transverse shear stress resultants, and $M_{11}^{\sigma}, M_{12}^{\sigma}, M_{22}^{\sigma}$ and $M_{21}^{\sigma}$ are the bending and torsional moments defined below:

$$
\begin{aligned}
\left\{N_{11}^{\sigma}, N_{12}^{\sigma}, Q_{13}^{\sigma}\right\} & =\int_{\zeta}\left\{\sigma_{11}, \sigma_{12}, k_{s} \sigma_{13}\right\}\left(1+\frac{\zeta}{R_{2}}\right) d \zeta \\
\left\{N_{22}^{\sigma}, N_{21}^{\sigma}, Q_{23}^{\sigma}\right\} & =\int_{\zeta}\left\{\sigma_{22}, \sigma_{21}, k_{s} \sigma_{23}\right\}\left(1+\frac{\zeta}{R_{1}}\right) d \zeta \\
\left\{M_{11}^{\sigma}, M_{12}^{\sigma}\right\} & =\int_{\zeta}\left\{\sigma_{11}, \sigma_{12}\right\} \zeta\left(1+\frac{\zeta}{R_{2}}\right) d \zeta \\
\left\{M_{22}^{\sigma}, M_{21}^{\sigma}\right\} & =\int_{\zeta}\left\{\sigma_{22}, \sigma_{21}\right\} \zeta\left(1+\frac{\zeta}{R_{1}}\right) d \zeta .
\end{aligned}
$$

It should be recalled that the definitions of the shear stress results require the introduction of the shear correction factor, which is usually taken as $k_{s}=5 / 6$. The same assumption is herein introduced for our analyses.

\section{Solution Procedure}

The Navier's approach is used to get the solution. The expressions below of the generalized displacements are considered for simply supported boundary conditions [36,37]:

$$
\begin{aligned}
u & =U \cos \left(\frac{m \pi}{a} \alpha_{1}\right) \cos \left(\frac{n \pi}{b} \alpha_{2}\right) e^{i \omega t} \\
v & =V \sin \left(\frac{m \pi}{a} \alpha_{1}\right) \sin \left(\frac{n \pi}{b} \alpha_{2}\right) e^{i \omega t} \\
w & =W \sin \left(\frac{m \pi}{a} \alpha_{1}\right) \cos \left(\frac{n \pi}{b} \alpha_{2}\right) e^{i \omega t} \\
\beta_{1} & =B_{1} \cos \left(\frac{m \pi}{a} \alpha_{1}\right) \cos \left(\frac{n \pi}{b} \alpha_{2}\right) e^{i \omega t} \\
\beta_{2} & =B_{2} \sin \left(\frac{m \pi}{a} \alpha_{1}\right) \sin \left(\frac{n \pi}{b} \alpha_{2}\right) e^{i \omega t},
\end{aligned}
$$

where $\omega$ represents a specific circular frequency of vibration. Moreover, $n$ and $m$ are the half-axial wave numbers along the $\alpha_{1}$ and $\alpha_{2}$ directions, respectively, whereas $U, V, W, B_{1}$, and $B_{2}$ are the vibrational amplitudes, collected in the corresponding vector $U=\left[\begin{array}{ll}U V B_{1} & B_{2}\end{array}\right]^{T}$. By substituting Equations (44)-(48) into Equations (34)-(38), we get to the following differential eigenvalue problem:

$$
\left[\boldsymbol{K}+\omega^{2} \boldsymbol{M}\right] \boldsymbol{U}=\mathbf{0},
$$

where $M$ and $K$ are mass and stiffness matrices, respectively. Achieving non-zero responses, the following condition should be satisfied:

$$
\operatorname{det}\left[\boldsymbol{K}+\omega^{2} \boldsymbol{M}\right]=0
$$

The solution of Equation (50) yields the natural frequencies. 


\section{Numerical Results and Discussion}

In this work we analyze the free vibration problem of FG spherical, hyperbolic paraboloidal, and circular cylindrical shells with porosities. For the sake of completeness, these geometries are schematically depicted in Figure 3.

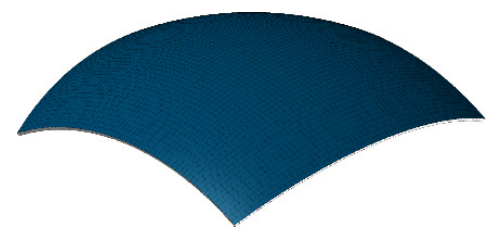

(a)

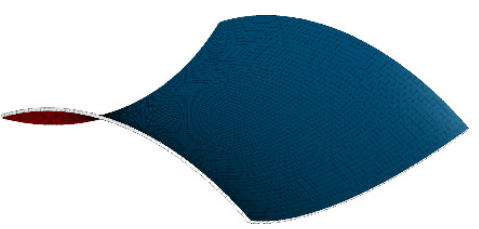

(b)

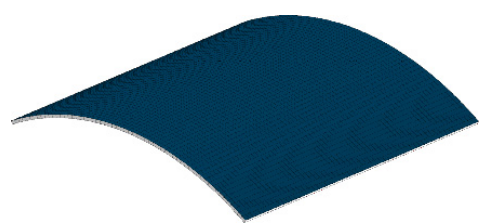

(c)

Figure 3. Geometries of shell structures considered in the applications: (a) Spherical shell; (b) hyperbolic paraboloidal shell; (c) circular cylindrical shell.

The FGM is considered to be the composition of metal (SUS304) and ceramic $\left(\mathrm{Al}_{2} \mathrm{O}_{3}\right)$, whose properties are provided in Table 1.

Table 1. Material properties of metal (SUS304) and ceramic $\left(\mathrm{Al}_{2} \mathrm{O}_{3}\right)$.

\begin{tabular}{ccccc}
\hline Material & $\boldsymbol{E}(\mathbf{G p a})$ & $\boldsymbol{v}$ & $\boldsymbol{\rho} \mathbf{( \mathbf { k g } / \mathbf { m } ^ { 3 } )}$ & Reference \\
\hline $\mathrm{SUS304}$ & 201.04 & 0.3262 & 8166 & {$[27,36,38]$} \\
$\mathrm{Al}_{2} \mathrm{O}_{3}$ & 349.55 & 0.24 & 3800 & {$[27,36,38]$} \\
\hline
\end{tabular}

In order to verify the accuracy of the proposed formulation, a comparative investigation is carried out against the existing results in the literature. For this reason, a simply supported isotropic spherical shell has been considered. In this case, we consider $a=b=1.0118 \mathrm{~m}, h=0.0191 \mathrm{~m}$, $R=R_{1}=R_{2}=1.91 \mathrm{~m}, E=1 \mathrm{~Pa}, \rho=1 \mathrm{~kg} / \mathrm{m}^{3}$, and $v=0.3$ [30]. Table 2 shows the main results in terms of natural frequencies for different modal shapes and wave numbers. As shown in Table 2, there is a very close agreement between results based on our proposed formulation and the predictions by Fadaee et al. [28] and Khare et al. [29].

Table 2. Comparison of the circular frequencies ( $\mathrm{rad} / \mathrm{s}$ ) for an isotropic simply-supported (SSSS) spherical shell.

\begin{tabular}{cccc}
\hline \multirow{2}{*}{ Mode $(\boldsymbol{m}, \boldsymbol{n})$} & \multicolumn{3}{c}{ Frequency } \\
\cline { 2 - 4 } & Present Study & Fadaee et al. [28] & Khare et al. [29] \\
\hline$(1,1)$ & 0.52692 & 0.52864 & 0.50211 \\
$(2,1)$ & 0.58120 & 0.58954 & 0.56247 \\
$(1,2)$ & 0.58120 & 0.58954 & 0.56248 \\
$(2,2)$ & 0.66757 & 0.68370 & 0.65706 \\
$(3,1)$ & 0.73173 & 0.75974 & 0.73915 \\
$(1,3)$ & 0.73173 & 0.75974 & 0.74035 \\
$(3,2)$ & 0.87284 & 0.88680 & 0.86359 \\
$(2,3)$ & 0.87284 & 0.88680 & 0.86360 \\
\hline
\end{tabular}

Hereafter, we define the frequencies in the dimensionless form as

$$
\hat{\omega}=\omega \frac{a^{2}}{h} \sqrt{\frac{\rho_{c}}{E_{c}}} .
$$

Tables 3-5 illustrate the dimensionless frequencies of FG porous spherical, hyperbolic paraboloidal, and circular cylindrical shells by using different values of the power-law index $p$ 
and porosity volume fraction $\beta$ for the FGM-types 1 and 2 power-law distributions. In particular, Table 3 shows the dimensionless frequency for a simply supported spherical shell with $a=b=1 \mathrm{~m}$, $R_{1}=R_{2}=1 \mathrm{~m}$ and thickness $h=0.01 \mathrm{~m}$. Four different wave numbers $(m, n)$ are considered, together with various $p$ and $\beta$ for two different ceramic volume fraction distributions. Table 4 shows similar results for the simply supported FG porous hyperbolic paraboloidal shell with $a=b=1 \mathrm{~m}$, thickness $h=0.01 \mathrm{~m}$, and curvatures $R_{1}=-R_{2}=1 \mathrm{~m}$.

In Table 5 we report the dimensionless frequencies of FG porous as functions of $p$ and $\beta$ for the circular cylindrical shell with simply supported boundary condition and square planform of $a=b=1 \mathrm{~m}$, thickness $h=0.01 \mathrm{~m}$, and curvatures $R_{1}=1, R_{2}=\infty$. Based on the results in Tables 3-5, the dimensionless frequency of FG porous shell structures can be easily modified by varying the power-law index $p$ and porosity volume fraction $\beta$. In more detail, the dimensionless frequencies for a FGM-type 1 are always higher than those related to an FGM-type 2. Similar behavior can be observed for hyperbolic paraboloidal and circular cylindrical shells (see Tables 4 and 5). For each structure analyzed here (i.e., spherical, hyperbolic paraboloidal, and circular cylindrical shell), we define the dimensionless frequencies as a function of $\beta$ for different wave numbers along the $\alpha_{1}$ and $\alpha_{2}$ directions, as well as for FGM-types 1 and 2, as depicted in Figures 4-6.

Table 3. Dimensionless frequency of simply-supported (SSSS) functionally graded porous spherical shell as functions of the power-law index and porosity volume fraction. FGM: Functionally Graded Material.

\begin{tabular}{|c|c|c|c|c|c|c|}
\hline \multicolumn{7}{|c|}{ FGM-Type 1 Power-Law Distribution } \\
\hline Porosity & Mode $(m, n)$ & $p=0$ & $p=0.3$ & $p=0.6$ & $p=1$ & $p=5$ \\
\hline \multirow{4}{*}{$(\beta=0)$} & $(1,1)$ & 96.2515 & 91.4707 & 73.5029 & 67.7563 & 54.9591 \\
\hline & $(2,2)$ & 100.8020 & 84.7121 & 76.6455 & 70.5771 & 57.4624 \\
\hline & $(3,3)$ & 108.5000 & 90.6464 & 81.7889 & 75.2368 & 61.6982 \\
\hline & $(4,4)$ & 126.0190 & 104.7290 & 94.2881 & 86.7258 & 71.8939 \\
\hline \multirow{4}{*}{$(\beta=0.1)$} & $(1,1)$ & 100.8150 & 92.4828 & 74.2942 & 67.8636 & 53.7906 \\
\hline & $(2,2)$ & 105.4450 & 86.5088 & 77.3459 & 70.5635 & 56.1427 \\
\hline & $(3,3)$ & 113.4500 & 92.4888 & 82.4393 & 75.1182 & 60.2263 \\
\hline & $(4,4)$ & 131.7140 & 106.7500 & 94.9017 & 86.4443 & 70.1336 \\
\hline \multirow{4}{*}{$(\beta=0.2)$} & $(1,1)$ & 107.0910 & 102.8620 & 75.2655 & 67.9668 & 52.3336 \\
\hline & $(2,2)$ & 111.8720 & 88.8384 & 78.2284 & 70.5396 & 54.5219 \\
\hline & $(3,3)$ & 120.3260 & 94.8992 & 83.2761 & 74.9779 & 58.4334 \\
\hline & $(4,4)$ & 139.6680 & 109.4300 & 95.7237 & 86.1258 & 68.0135 \\
\hline \multicolumn{7}{|c|}{ FGM-type 2 Power-law distribution } \\
\hline Porosity & Mode $(m, n)$ & $p=0$ & $p=0.3$ & $p=0.6$ & $p=1$ & $p=5$ \\
\hline \multirow{4}{*}{$(\beta=0)$} & $(1,1)$ & 96.2515 & 90.7627 & 73.8184 & 68.1096 & 55.2069 \\
\hline & $(2,2)$ & 100.8020 & 85.5775 & 77.8421 & 71.9234 & 58.4065 \\
\hline & $(3,3)$ & 108.5000 & 92.4549 & 84.2883 & 78.0465 & 63.6580 \\
\hline & $(4,4)$ & 126.0190 & 109.6880 & 98.1258 & 91.0358 & 74.8731 \\
\hline \multirow{4}{*}{$(\beta=0.1)$} & $(1,1)$ & 100.8150 & 91.2313 & 74.6290 & 68.2372 & 54.0529 \\
\hline & $(2,2)$ & 105.4450 & 87.4252 & 78.6036 & 71.9729 & 57.1317 \\
\hline & $(3,3)$ & 113.4500 & 94.4013 & 85.0632 & 78.0563 & 62.2761 \\
\hline & $(4,4)$ & 131.7140 & 109.6880 & 98.9337 & 90.9554 & 73.2497 \\
\hline \multirow{4}{*}{$(\beta=0.2)$} & $(1,1)$ & 107.0910 & 102.4517 & 75.6247 & 68.3659 & 52.6147 \\
\hline & $(2,2)$ & 111.8720 & 89.8218 & 78.2284 & 70.5396 & 54.5219 \\
\hline & $(3,3)$ & 120.3260 & 96.9495 & 86.0617 & 78.0819 & 60.6011 \\
\hline & $(4,4)$ & 139.6680 & 112.580 & 100.0080 & 90.8967 & 71.3080 \\
\hline
\end{tabular}


According to Figures 4-6, it is worth noting that the dimensionless frequencies increase in value for shells made of pure ceramic (i.e., $p=0$ ). This is due to the fact that ceramic $\left(\mathrm{Al}_{2} \mathrm{O}_{3}\right)$ features a higher Young's modulus than metal (SUS304). The most important result that can be inferred from Figures 4-6 is that an increased porosity volume fraction leads to an increased dimensionless frequency for a rich ceramic limit. The variation of the dimensionless frequency parameters for mode $(1,1)$ with respect to the power-law index $p$ for three various values of porosity volume fraction (i.e., $\beta=0$, $\beta=0.1$, and $\beta=0.3$ ) in FGM-types 1 and 2, are plotted in Figures 7-9 for a spherical, hyperbolic paraboloidal, and circular cylindrical shell, respectively.

As shown in Figures 7-9, the dimensionless frequency increases monotonically with the porosity volume fraction $\beta$, but decreases for an increasing power-law index. For instance, between $p=0$ and $p \approx 1$, the dimensionless frequencies increase with an increasing porosity volume fraction $\beta$, whereas after $p=1$ they decrease with the increase in $\beta$. This behavior can be observed for all the modes $(m, n)$. As seen in Figures 7-9, for each structure there is a rapid decrease of frequencies between $p=0$ (limit case of pure ceramic) and approximately $p=1$. For $p$ higher than 1 , the declining trend goes much more slowly. Similar behavior is observed for all the structures studied here and for all modes $(m, n)$.

Table 4. Dimensionless frequency of simply-supported (SSSS) functionally graded porous hyperbolic paraboloidal shell as functions of the power-law index and porosity volume fraction.

\begin{tabular}{|c|c|c|c|c|c|c|}
\hline \multicolumn{7}{|c|}{ FGM-1 Power-Law Distribution } \\
\hline Porosity & Mode $(m, n)$ & $p=0$ & $p=0.3$ & $p=0.6$ & $p=1$ & $p=5$ \\
\hline \multirow{4}{*}{$(\beta=0)$} & $(1,1)$ & 3.9944 & 3.3438 & 3.0276 & 2.8052 & 2.3793 \\
\hline & $(2,2)$ & 18.5237 & 15.5060 & 14.0398 & 13.0083 & 11.0330 \\
\hline & $(3,3)$ & 42.7974 & 35.8247 & 32.4370 & 30.0536 & 25.4874 \\
\hline & $(4,4)$ & 76.6832 & 64.1885 & 58.1186 & 53.8474 & 45.6605 \\
\hline \multirow{4}{*}{$(\beta=0.1)$} & $(1,1)$ & 4.1700 & 3.4012 & 3.0393 & 2.7886 & 2.3225 \\
\hline & $(2,2)$ & 19.3382 & 15.7725 & 14.0941 & 12.9312 & 10.7696 \\
\hline & $(3,3)$ & 44.6804 & 36.4414 & 32.5633 & 29.8764 & 24.8799 \\
\hline & $(4,4)$ & 80.0601 & 65.2962 & 58.3473 & 53.5324 & 44.5732 \\
\hline \multirow{4}{*}{$(\beta=0.2)$} & $(1,1)$ & 4.41884 & 3.4809 & 3.05829 & 2.7712 & 2.2566 \\
\hline & $(2,2)$ & 20.4929 & 16.1423 & 14.1826 & 12.8511 & 10.4639 \\
\hline & $(3,3)$ & 47.3497 & 37.2966 & 32.769 & 29.6925 & 24.1744 \\
\hline & $(4,4)$ & 84.8460 & 66.8307 & 58.7183 & 53.2052 & 43.3115 \\
\hline \multicolumn{7}{|c|}{ FGM-2 Power-law distribution } \\
\hline Porosity & Mode $(m, n)$ & $p=0$ & $p=0.3$ & $p=0.6$ & $p=1$ & $p=5$ \\
\hline \multirow{4}{*}{$(\beta=0)$} & $(1,1)$ & 3.9944 & 3.3452 & 3.0297 & 2.8076 & 2.3810 \\
\hline & $(2,2)$ & 18.5237 & 15.5136 & 14.0507 & 13.0208 & 11.0420 \\
\hline & $(3,3)$ & 42.7974 & 35.8428 & 32.4627 & 30.0831 & 25.5091 \\
\hline & $(4,4)$ & 76.6832 & 64.2209 & 58.1647 & 53.9003 & 45.6995 \\
\hline \multirow{4}{*}{$(\beta=0.1)$} & $(1,1)$ & 4.1700 & 3.40289 & 3.04161 & 2.79127 & 2.32458 \\
\hline & $(2,2)$ & 19.3382 & 15.7814 & 14.1061 & 12.9450 & 10.7798 \\
\hline & $(3,3)$ & 44.6804 & 36.4616 & 32.5917 & 29.9089 & 24.9039 \\
\hline & $(4,4)$ & 80.0601 & 65.3321 & 58.3983 & 53.5908 & 44.6171 \\
\hline \multirow{4}{*}{$(\beta=0.2)$} & $(1,1)$ & 4.41884 & 3.4828 & 3.0610 & 2.7743 & 2.2590 \\
\hline & $(2,2)$ & 20.4929 & 16.1518 & 14.1962 & 12.8666 & 10.4754 \\
\hline & $(3,3)$ & 47.3497 & 37.3192 & 32.8007 & 29.7287 & 24.2014 \\
\hline & $(4,4)$ & 84.8460 & 66.8714 & 58.7752 & 53.2703 & 43.3601 \\
\hline
\end{tabular}


Table 5. Dimensionless frequency of simply-supported (SSSS) functionally graded porous circular cylindrical shell as functions of the power-law index and porosity volume fraction.

\begin{tabular}{|c|c|c|c|c|c|c|}
\hline \multicolumn{7}{|c|}{ FGM-1 Power-Law Distribution } \\
\hline Porosity & Mode $(m, n)$ & $p=0$ & $p=0.3$ & $p=0.6$ & $p=1$ & $p=5$ \\
\hline \multirow{4}{*}{$(\beta=0)$} & $(1,1)$ & 48.4942 & 40.8660 & 37.0253 & 34.1183 & 27.7268 \\
\hline & $(2,2)$ & 53.0808 & 44.3991 & 40.0824 & 36.8778 & 30.1956 \\
\hline & $(3,3)$ & 65.9875 & 54.7970 & 49.3207 & 45.3731 & 37.7164 \\
\hline & $(4,4)$ & 91.8995 & 76.1928 & 68.5752 & 63.1903 & 53.1539 \\
\hline \multirow{4}{*}{$(\beta=0.1)$} & $(1,1)$ & 50.7297 & 41.7402 & 37.3740 & 34.1238 & 27.0979 \\
\hline & $(2,2)$ & 55.500 & 45.3040 & 40.4061 & 36.8257 & 29.4760 \\
\hline & $(3,3)$ & 68.9586 & 55.8377 & 49.6220 & 45.2055 & 36.7869 \\
\hline & $(4,4)$ & 95.9954 & 77.5601 & 68.8955 & 62.8567 & 51.8369 \\
\hline \multirow{4}{*}{$(\beta=0.2)$} & $(1,1)$ & 53.8218 & 42.8723 & 37.8124 & 34.1267 & 26.3250 \\
\hline & $(2,2)$ & 58.8601 & 46.4870 & 40.8218 & 36.7640 & 28.5992 \\
\hline & $(3,3)$ & 73.1141 & 57.2240 & 50.0319 & 45.0178 & 35.6715 \\
\hline & $(4,4)$ & 101.7600 & 79.4159 & 69.3675 & 62.4923 & 50.2788 \\
\hline \multicolumn{7}{|c|}{ FGM-2 Power-law distribution } \\
\hline Porosity & Mode $(m, n)$ & $p=0$ & $p=0.3$ & $p=0.6$ & $p=1$ & $p=5$ \\
\hline \multirow{4}{*}{$(\beta=0)$} & $(1,1)$ & 48.4942 & 41.0805 & 37.3222 & 34.4526 & 27.9614 \\
\hline & $(2,2)$ & 53.0808 & 45.2115 & 41.2050 & 38.1398 & 31.0770 \\
\hline & $(3,3)$ & 65.9875 & 56.2839 & 51.3764 & 47.6810 & 39.3077 \\
\hline & $(4,4)$ & 91.8995 & 78.1084 & 71.2254 & 66.1625 & 55.1808 \\
\hline \multirow{4}{*}{$(\beta=0.1)$} & $(1,1)$ & 50.7297 & 41.9677 & 37.6866 & 34.4744 & 27.3442 \\
\hline & $(2,2)$ & 55.500 & 46.1629 & 41.5841 & 38.1448 & 30.3976 \\
\hline & $(3,3)$ & 68.9586 & 57.4109 & 51.7815 & 47.6209 & 38.4507 \\
\hline & $(4,4)$ & 95.9954 & 79.5895 & 71.6842 & 65.9730 & 53.9575 \\
\hline \multirow{4}{*}{$(\beta=0.2)$} & $(1,1)$ & 53.8218 & 43.1169 & 38.1453 & 34.4984 & 26.5867 \\
\hline & $(2,2)$ & 58.8601 & 47.4074 & 42.0719 & 38.1571 & 29.5735 \\
\hline & $(3,3)$ & 73.1141 & 58.9107 & 52.3262 & 47.5720 & 37.4298 \\
\hline & $(4,4)$ & 101.760 & 81.5943 & 72.3353 & 65.7942 & 52.5205 \\
\hline
\end{tabular}
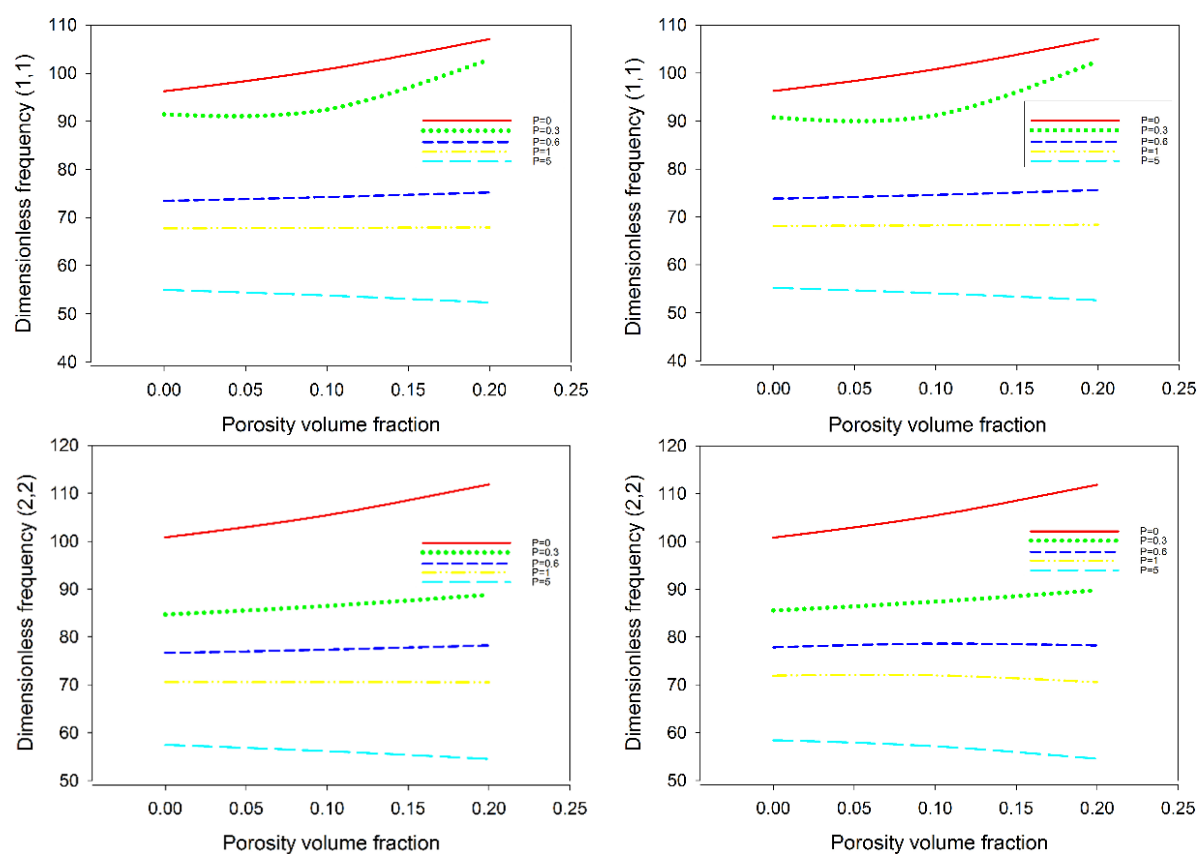

Figure 4. Cont. 

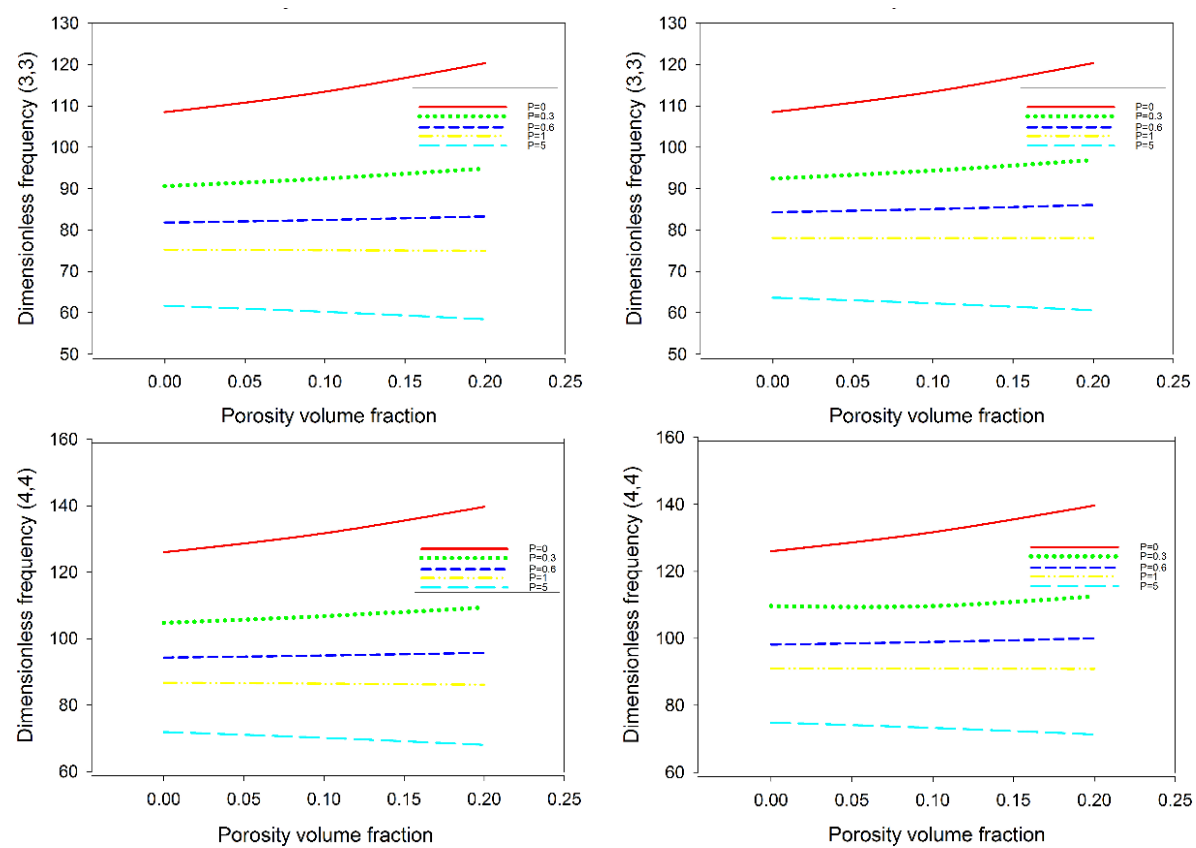

(a) FGM-type 1

(b) FGM-type 2

Figure 4. Dimensionless frequency of FG porous spherical shell against different power-law indices and porosity volume fractions distributions: (a) FGM-type 1; (b) FGM-type 2.
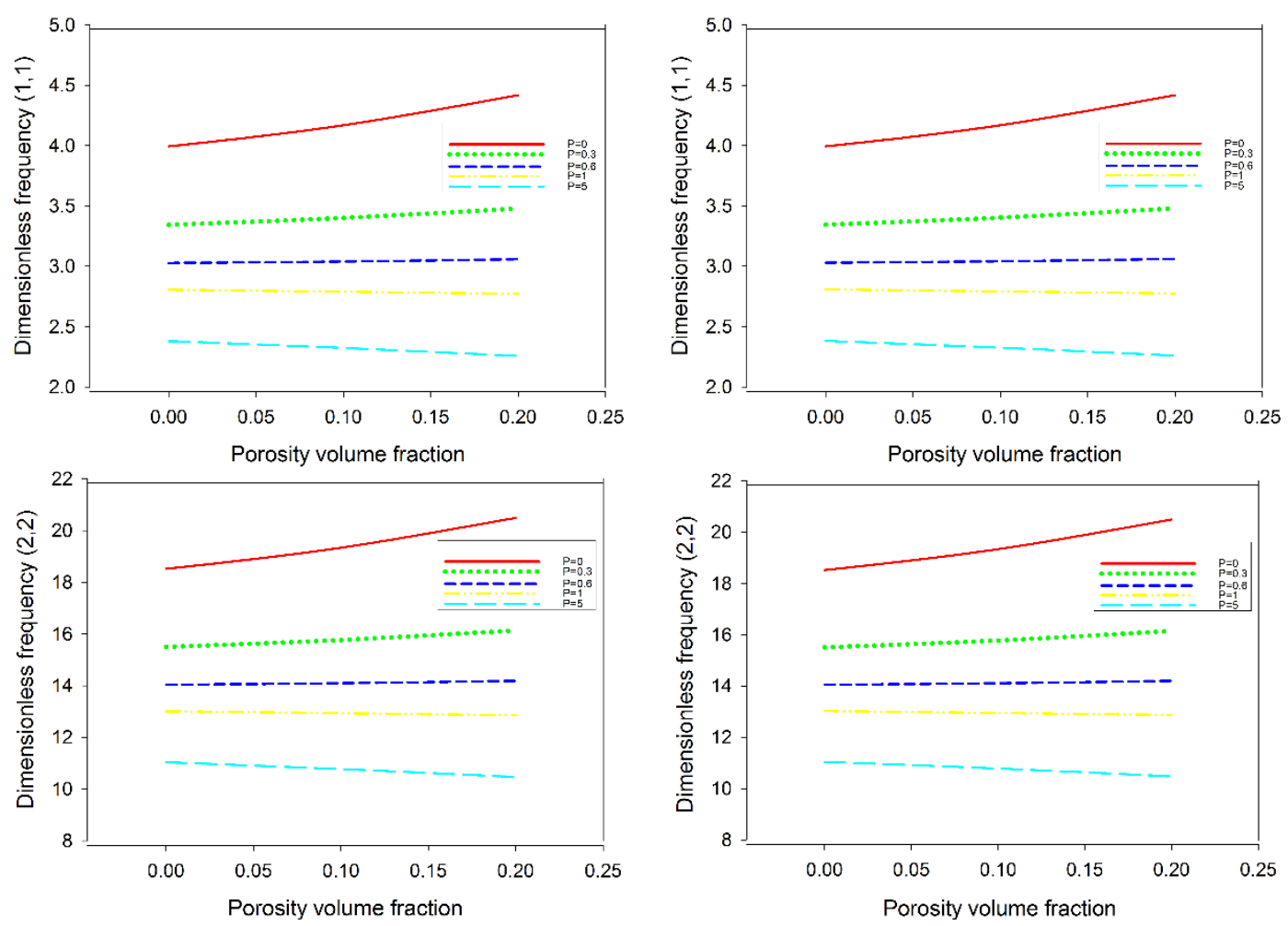

Figure 5. Cont. 

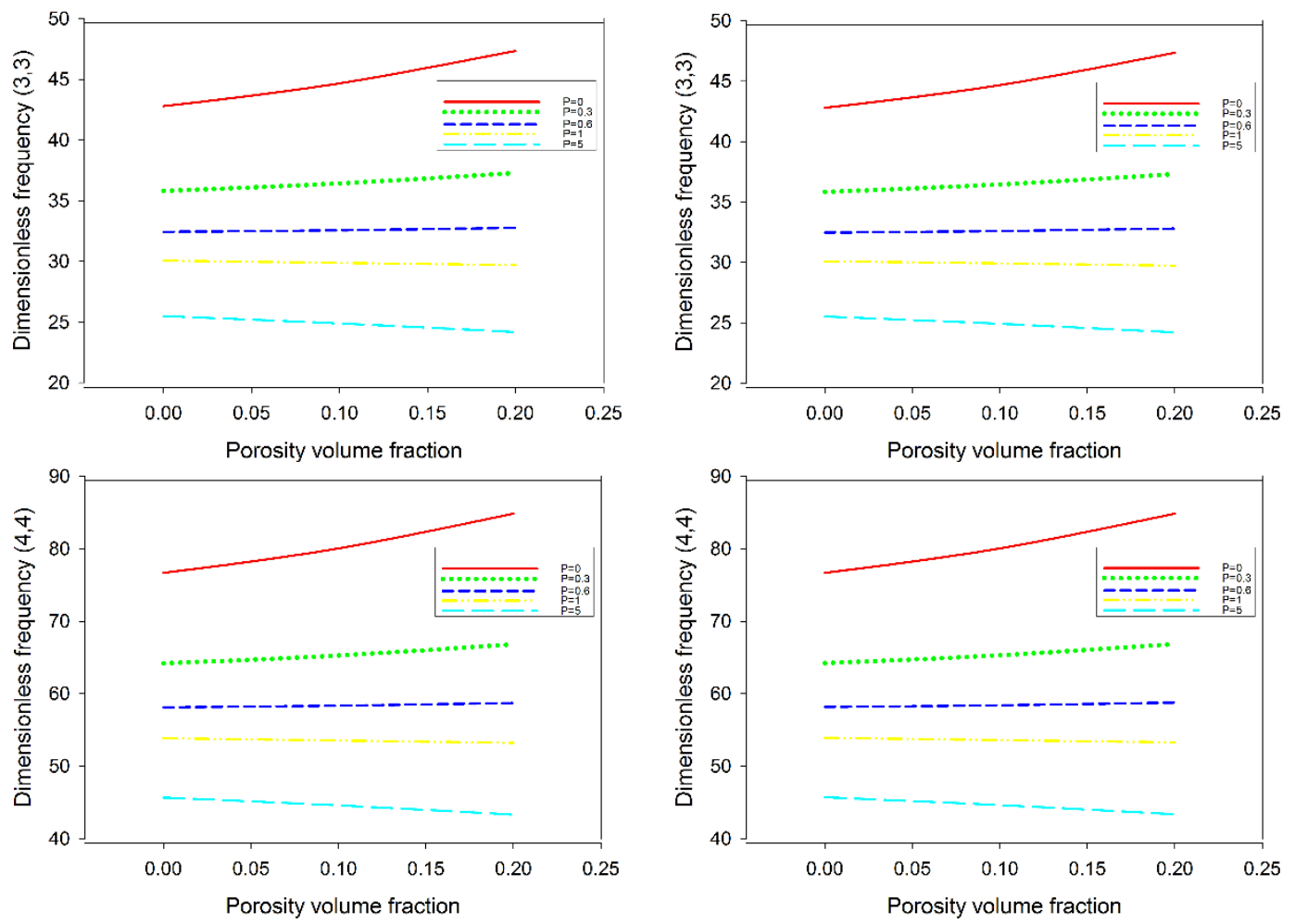

(a) FGM-type 1

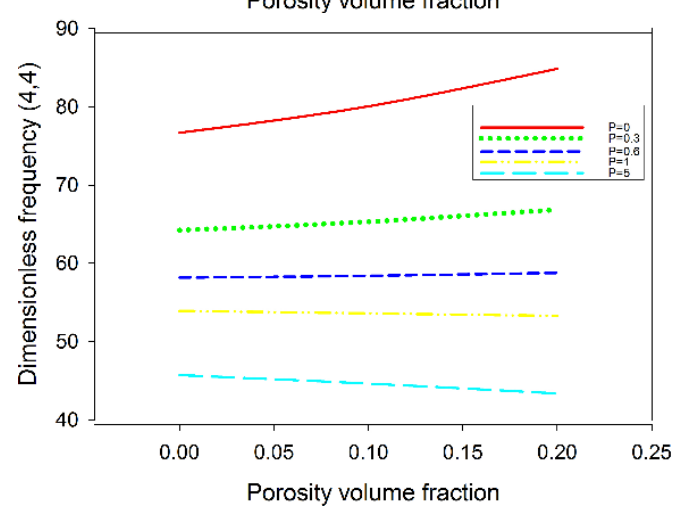

(b) FGM-type 2

Figure 5. Dimensionless frequency of FG porous hyperbolic paraboloidal shell against different power-law indices and porosity volume fractions distributions: (a) FGM-type 1; (b) FGM-type 2.
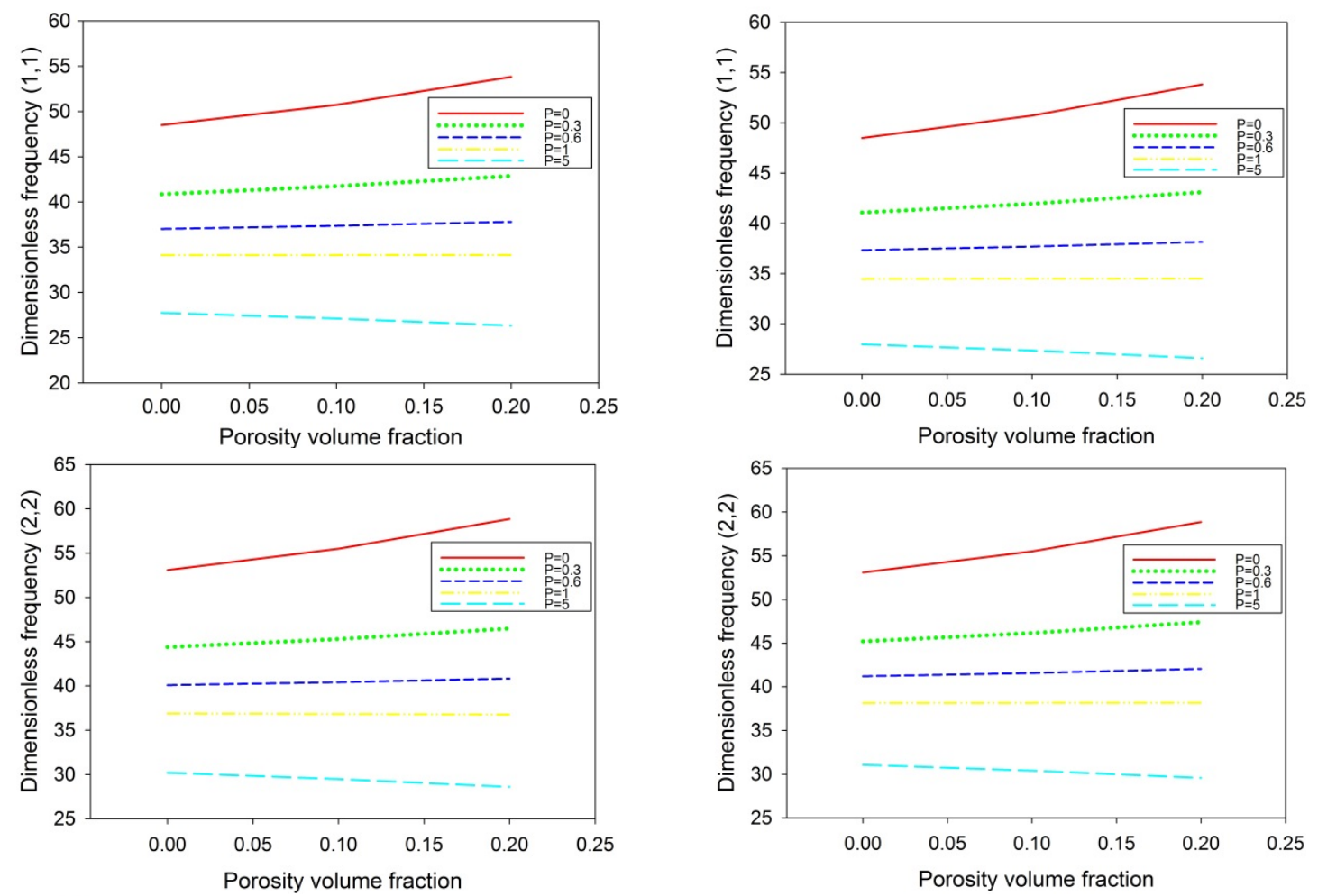

Figure 6. Cont. 

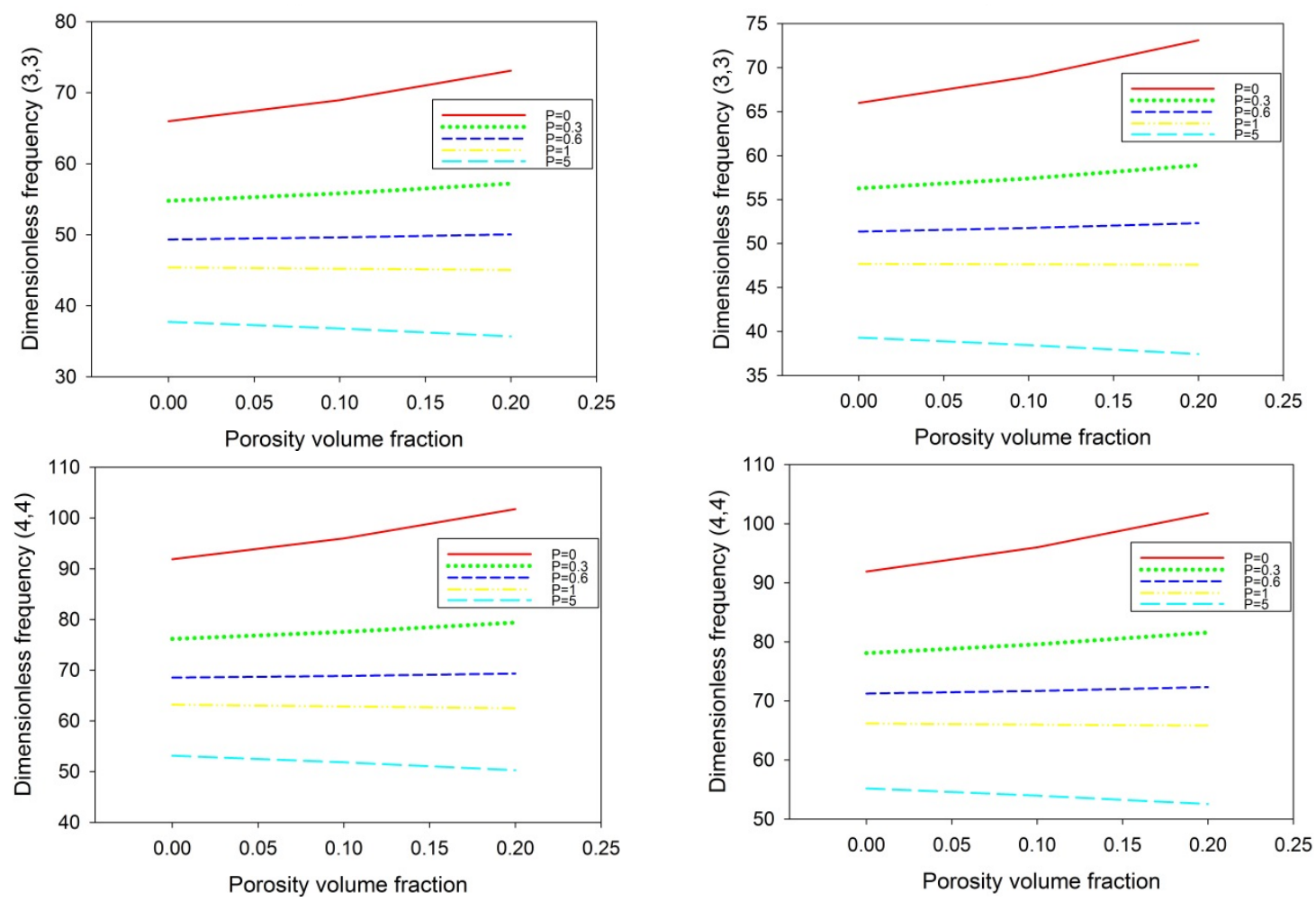

(a) FGM-type 1

(b) FGM-type 2

Figure 6. Dimensionless frequency of FG porous hyperbolic circular cylindrical shell against different power-law indices and porosity volume fractions distributions: (a) FGM-type 1; (b) FGM-type 2.

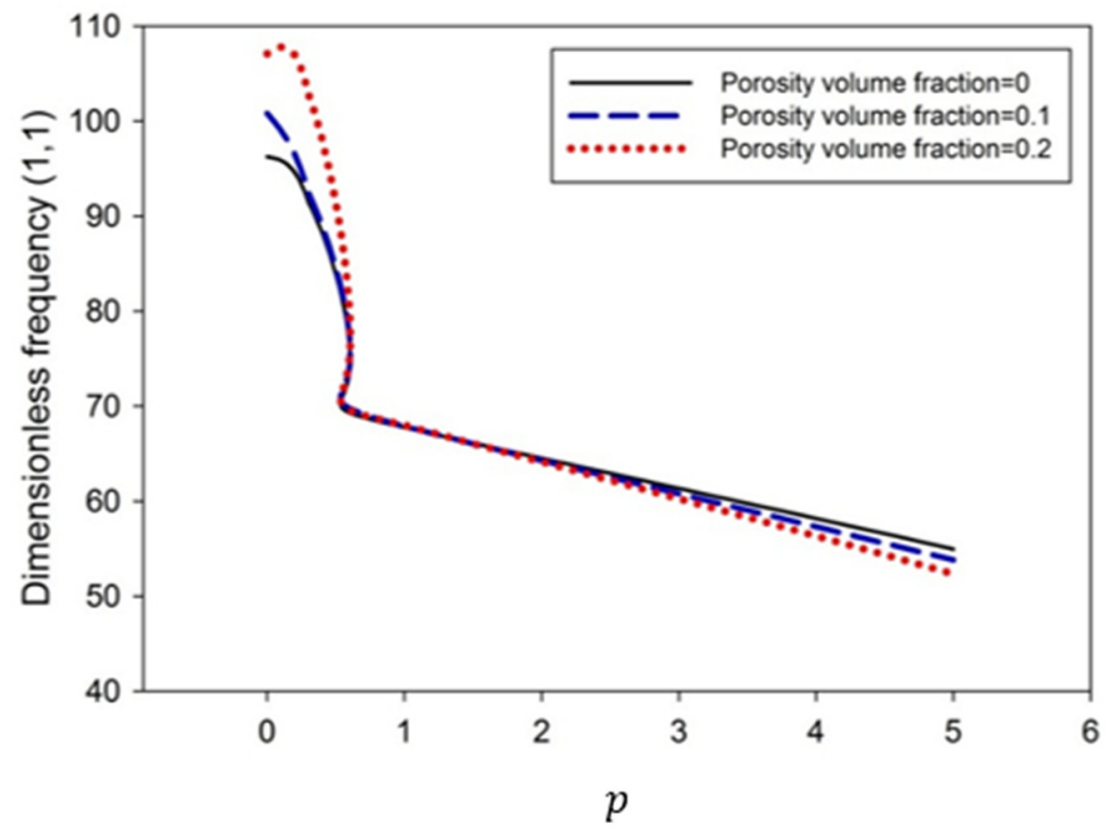

(a) FGM-type 1

Figure 7. Cont. 


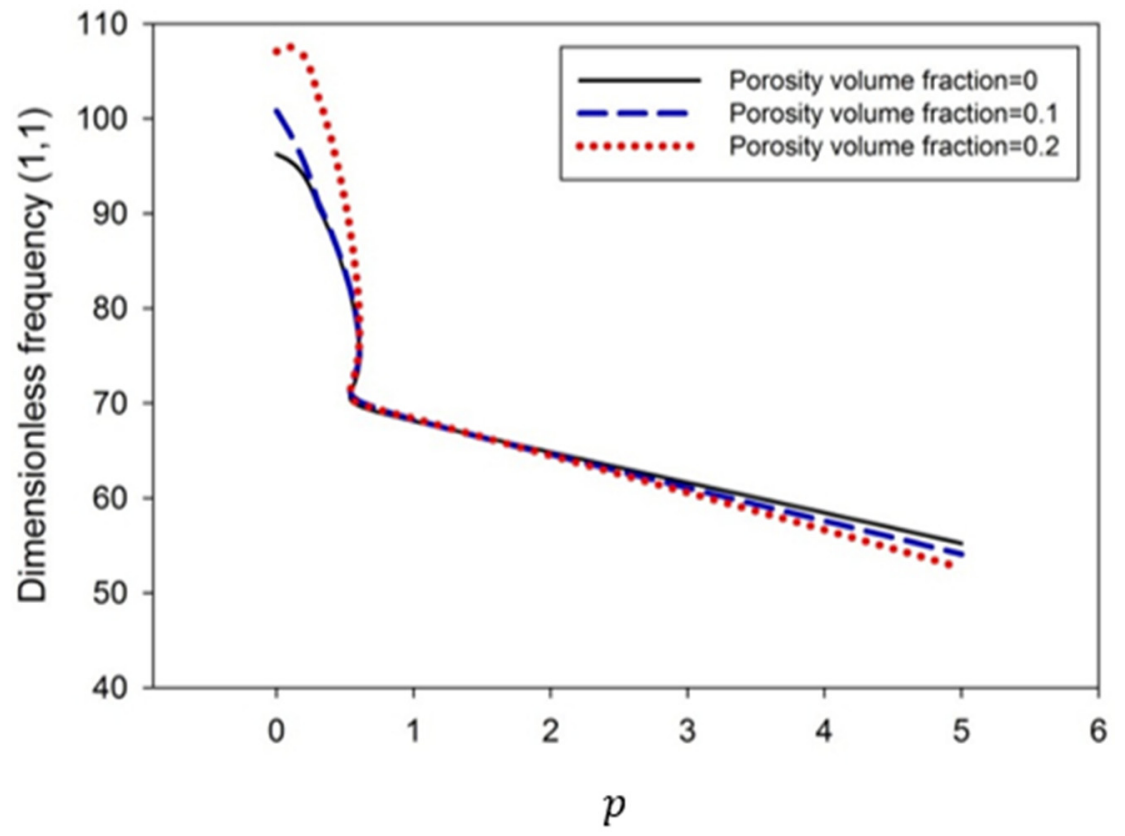

(b) FGM-type 2

Figure 7. Dimensionless frequency of FG porous spherical shell versus different power-law indices for various porosity volume fractions: (a) FGM-type 1, (b) FGM-type 2.

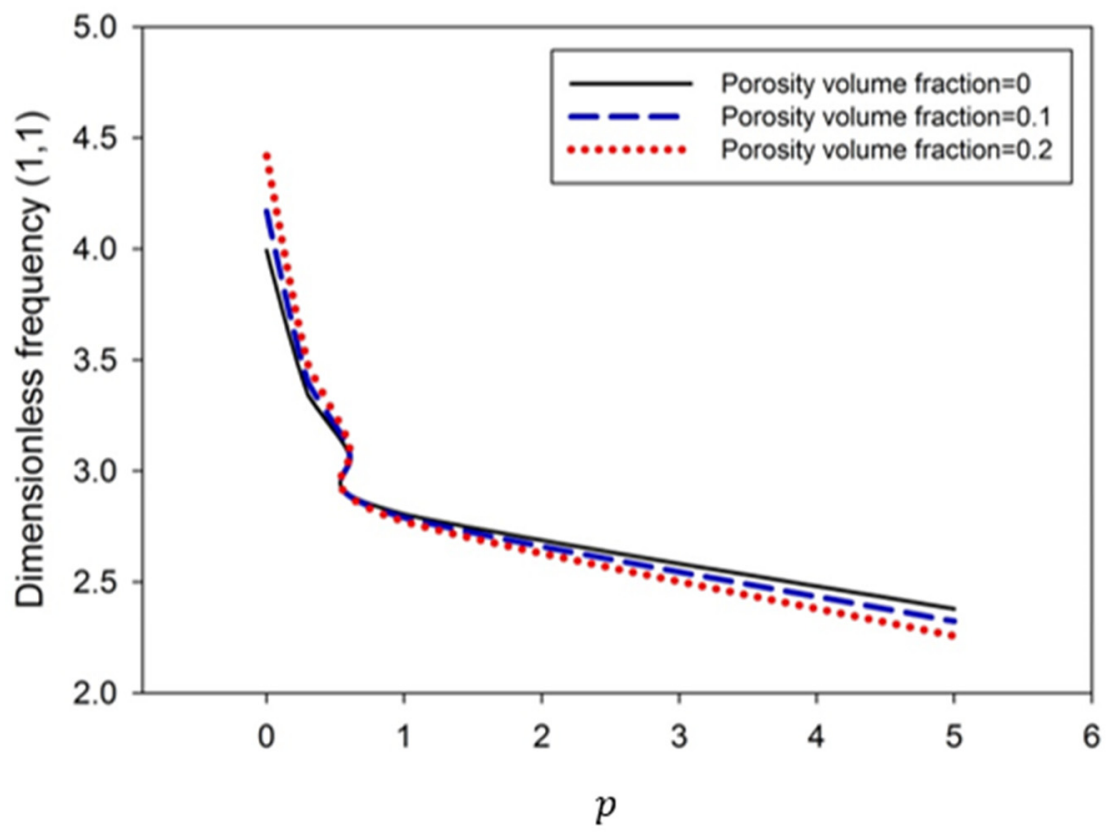

(a) FGM-type 1

Figure 8. Cont. 


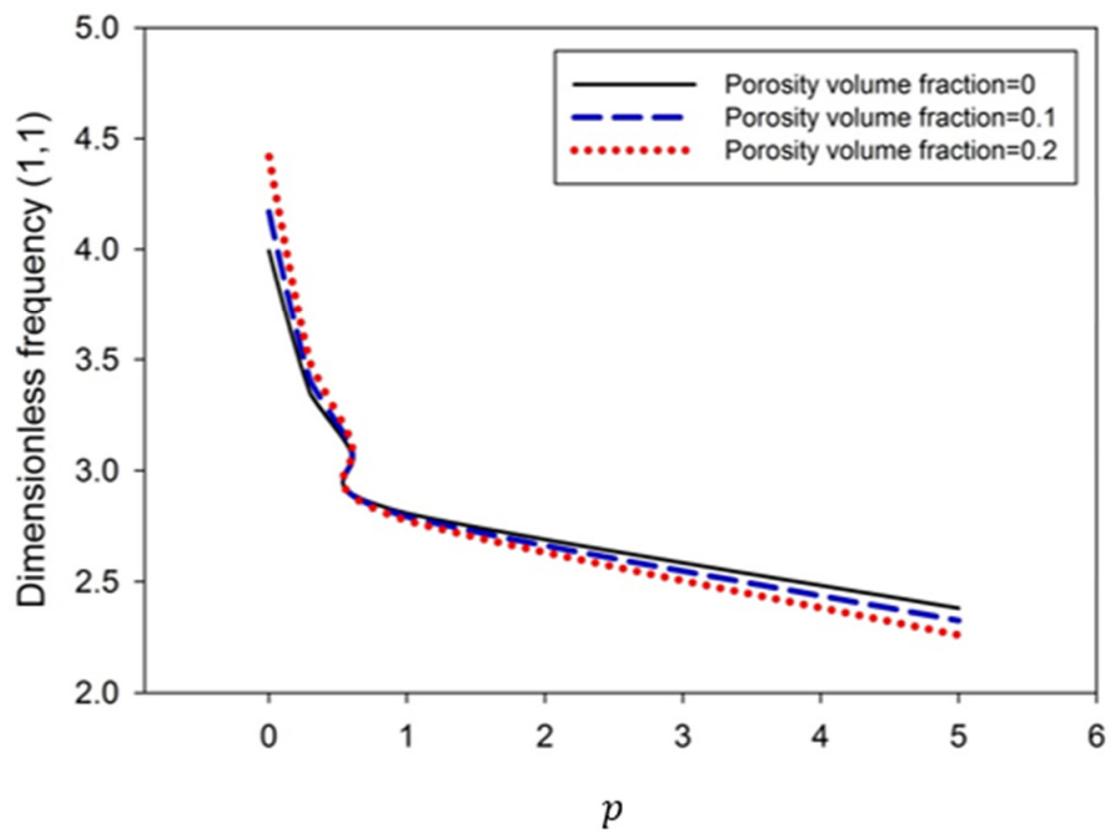

(b) FGM-type 2

Figure 8. Dimensionless frequency of FG porous hyperbolic paraboloidal shell versus different power-law indices for various porosity volume fractions: (a) FGM-type 1; (b) FGM-type 2.

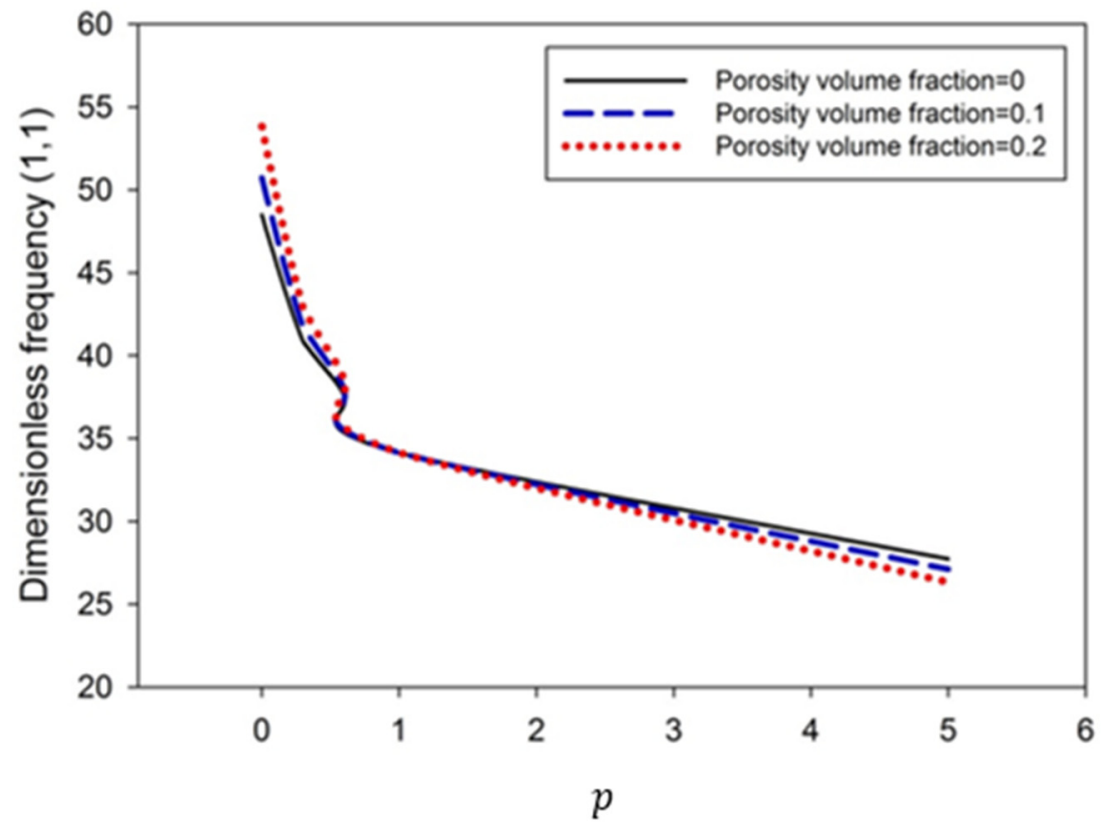

(a) FGM-type 1

Figure 9. Cont. 


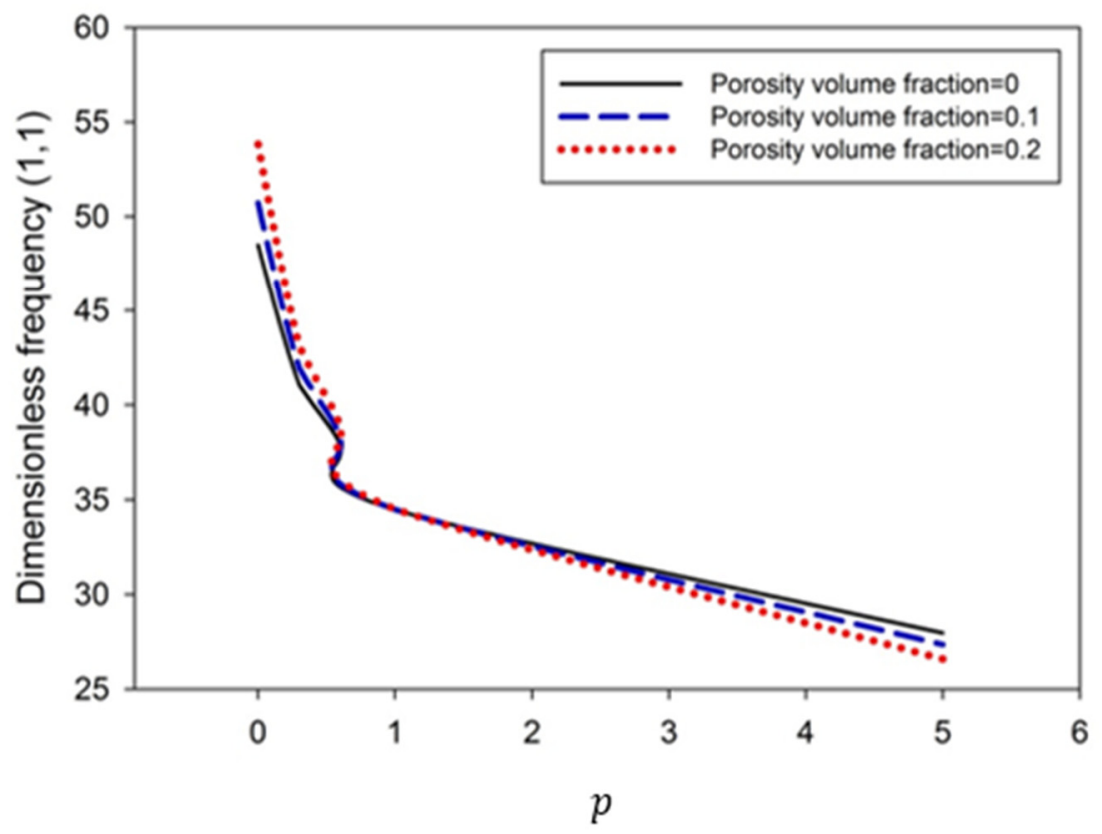

(b) FGM-type 2

Figure 9. Dimensionless frequency of FG porous circular cylindrical shell versus different power-law indices for various porosity volume fractions: (a) FGM-type 1; (b) FGM-type 2.

\section{Conclusions}

The dynamic equilibrium equations of FG porous doubly-curved shells have been derived by means of the Hamilton's principle. FSDT is used to study the shell theory. FG shells with two various ceramic volume fraction distributions are considered, in the presence of an even distribution of porosities. Navier's solution method is employed here to solve the equations of motion and a comparative study is performed to verify the accuracy of our results. We analyze the free vibration behavior of three special cases of FG doubly-curved shells (spherical shell, hyperbolic paraboloidal shell, and circular cylindrical shell). All the results reveal that the porosity and a combined distribution of ceramic and metal during manufacturing can significantly affect the mechanical behavior of FGM-based structures. In particular, between $p=0$ and $p \approx 1$, the dimensionless frequencies for all the structures increase by increasing the porosity volume fraction, while changing their trend after $p \approx 1$. The natural frequencies are revealed to reach the maximum value for a pure ceramic material $(p=0)$ while declining for increasing $p$ or within metallic materials. Finally, it should be mentioned that different tendencies and mechanical behaviors can be obtained if different geometries are considered. In fact, the curvature effect could cause the coupling of membrane and bending behaviors. Thus, a different dynamic response could be obtained if various structures characterized by different values of curvature radii (such as spherical, hyperbolic paraboloidal, and cylindrical shells) are analyzed. This coupling could be even more accentuated for peculiar mechanical configurations, as in the case of FGMs.

Author Contributions: Farajollah Zare Jouneghani, Rossana Dimitri, Michele Bacciocchi and Francesco Tornabene contributed equally to the development of the research topic and to the writing of the manuscript.

Conflicts of Interest: The authors declare no conflict of interest. The founding sponsors had no role in the design of the study; in the collection, analyses, or interpretation of data; in the writing of the manuscript, and in the decision to publish the results. 


\section{References}

1. Niino, M.; Hirai, T.; Watanabe, R. The functionally gradient materials. J. Jpn. Soc. Comp. Mater. 1987, $13,257$. [CrossRef]

2. Wattanasakulpong, N.; Chaikittiratana, A. An analytical investigation on free vibration of FGM doubly curved shallow shells with stiffeners under thermal environment. Aerosp. Sci. Technol. 2015, 40, 181-190. [CrossRef]

3. Tornabene, F.; Fantuzzi, N.; Bacciocchi, M. Free vibrations of free-form doubly-curved shells made of functionally graded materials using higher-order equivalent single layer theories. Compos. Part B Eng. 2014, 67, 490-509. [CrossRef]

4. Kiani, Y.; Akbarzadeh, A.H.; Chen, Z.T.; Eslami, M.R. Static and dynamic analysis of an FGM doubly curved panel resting on the Pasternak-type elastic foundation. Compos. Struct. 2012, 94, 2474-2484. [CrossRef]

5. Kiani, Y.; Sadighi, M.; Eslami, M. Dynamic analysis and active control of smart doubly curved FGM panels. Compos. Struct. 2013, 102, 205-216. [CrossRef]

6. Sayyaadi, H.; Farsangi, M.A.A. An analytical solution for dynamic behavior of thick doubly curved functionally graded smart panels. Compos. Struct. 2014, 107, 88-102. [CrossRef]

7. Wang, Y.Q.; Zu, J.W. Vibration behaviors of functionally graded rectangular plates with porosities and moving in thermal environment. Aerosp. Sci. Technol. 2017, 69, 550-562. [CrossRef]

8. Shafiei, N.; Kazemi, M. Buckling analysis on the bi-dimensional functionally graded porous tapered nano-/micro-scale beams. Aerosp. Sci. Technol. 2017, 66, 1-11. [CrossRef]

9. Shafiei, N.; Kazemi, M. Nonlinear buckling of functionally graded nano-/micro-scaled porous beams. Compos. Struct. 2017, 178, 483-492. [CrossRef]

10. Shahverdi, H.; Barati, M.R. Vibration analysis of porous functionally graded nanoplates. Int. J. Eng. Sci. 2017, 120, 82-99. [CrossRef]

11. Tornabene, F. Free vibrations of anisotropic doubly-curved shells and panels of revolution with a free-form meridian resting on Winkler-Pasternak elastic foundations. Compos. Struct. 2011, 94, 186-206. [CrossRef]

12. Tornabene, F.; Liverani, A.; Caligiana, G. FGM and laminated doubly curved shells and panels of revolution with a free-form meridian: A 2-D GDQ solution for free vibrations. Int. J. Mech. Sci. 2011, 53, 446-470. [CrossRef]

13. Tornabene, F.; Liverani, A.; Caligiana, G. General anisotropic doubly-curved shell theory: A differential quadrature solution for free vibrations of shells and panels of revolution with a free-form meridian. J. Sound Vib. 2012, 331, 4848-4869. [CrossRef]

14. Viola, E.; Tornabene, F.; Fantuzzi, N. Static analysis of completely doubly-curved laminated shells and panels using general higher-order shear deformation theories. Compos. Struct. 2013, 101, 59-93. [CrossRef]

15. Tornabene, F.; Viola, E.; Fantuzzi, N. General higher-order equivalent single layer theory for free vibrations of doubly-curved laminated composite shells and panels. Compos. Struct. 2013, 104, 94-117. [CrossRef]

16. Tornabene, F.; Fantuzzi, N.; Bacciocchi, M. The local GDQ method applied to general higher-order theories of doubly-curved laminated composite shells and panels: The free vibration analysis. Compos. Struct. 2014, 116, 637-660. [CrossRef]

17. Tornabene, F.; Fantuzzi, N.; Bacciocchi, M.; Viola, E. Accurate inter-laminar recovery for plates and doubly-curved shells with variable radii of curvature using layer-wise theories. Compos. Struct. 2015, 124, 368-393. [CrossRef]

18. Tornabene, F.; Fantuzzi, N.; Bacciocchi, M.; Neves, A.M.A.; Ferreira, A.J.M. MLSDQ based on RBFs for the free vibrations of laminated composite doubly-curved shells. Compos. Part B Eng. 2016, 99, 30-47. [CrossRef]

19. Tornabene, F.; Fantuzzi, N.; Bacciocchi, M. A New Doubly-Curved Shell Element for the Free Vibrations of Arbitrarily Shaped Laminated Structures Based on Weak Formulation Isogeometric Analysis. Compos. Struct. 2017, 171, 429-461. [CrossRef]

20. Tornabene, F.; Fantuzzi, N.; Bacciocchi, M.; Viola, E.; Reddy, J.N. A Numerical Investigation on the Natural Frequencies of FGM Sandwich Shells with Variable Thickness by the Local Generalized Differential Quadrature Method. Appl. Sci. 2017, 7, 131. [CrossRef]

21. Amabili, M. A new nonlinear higher-order shear deformation theory with thickness variation for large-amplitude vibrations of laminated doubly curved shells. J. Sound Vib. 2013, 332, 4620-4640. [CrossRef]

22. Amabili, M. A new third-order shear deformation theory with non-linearities in shear for static and dynamic analysis of laminated doubly curved shells. Compos. Struct. 2015, 128, 260-273. [CrossRef] 
23. Amabili, M. Non-linearities in rotation and thickness deformation in a new third-order thickness deformation theory for static and dynamic analysis of isotropic and laminated doubly curved shells. Int. J. Nonlinear Mech. 2015, 69, 109-128. [CrossRef]

24. Amabili, M. A non-linear higher-order thickness stretching and shear deformation theory for large-amplitude vibrations of laminated doubly curved shells. Int. J. Nonlinear Mech. 2014, 58, 57-75. [CrossRef]

25. Amabili, M.; Reddy, J.N. A new non-linear higher-order shear deformation theory for large-amplitude vibrations of laminated doubly curved shells. Int. J. Nonlinear Mech. 2010, 45, 409-418. [CrossRef]

26. Tornabene, F.; Fantuzzi, N.; Bacciocchi, M.; Viola, E. Effect of agglomeration on the natural frequencies of functionally graded carbon nanotube-reinforced laminated composite doubly-curved shells. Compos. Part B Eng. 2016, 89, 187-218. [CrossRef]

27. Amabili, M. Nonlinear Vibrations and Stability of Shells and Plates; Cambridge University Press: New York, NY, USA, 2008.

28. Fadaee, M.; Atashipour, S.; Hosseini-Hashemi, S. Free vibration analysis of Lévy-type functionally graded spherical shell panel using a new exact closed-form solution. Int. J. Mech. Sci. 2013, 77, 227-238. [CrossRef]

29. Khare, R.K.; Kant, T.; Garg, A.K. Free vibration of composite and sandwich laminates with a higher-order facet shell element. Compos. Struct. 2004, 65, 405-418. [CrossRef]

30. Wattanasakulpong, N.; Gangadhara Prusty, B.; Kelly, D.W.; Hoffman, M. Free vibration analysis of layered functionally graded beams with experimental validation. Mater. Design 2012, 36, 182-190. [CrossRef]

31. Wattanasakulpong, N.; Ungbhakorn, V. Linear and nonlinear vibration analysis of elastically restrained ends FGM beams with porosities. Aerosp. Sci. Technol. 2014, 32, 111-120. [CrossRef]

32. Wattanasakulpong, N.; Chaikittiratana, A. Flexural vibration of imperfect functionally graded beams based on Timoshenko beam theory: Chebyshev collocation method. Meccanica 2015, 50, 1331-1342. [CrossRef]

33. Shafiei, N.; Mirjavadi, S.S.; Afshari, B.M.; Rabby, S.; Kazemi, M. Vibration of two-dimensional imperfect functionally graded (2D-FG) porous nano-/micro-beams. Comput. Methods Appl. Mech 2017, 322, 615-632. [CrossRef]

34. Ebraimi, F.; Zia, M. Large amplitude nonlinear vibration analysis of functionally graded Timoshenko beams with porosities. Acta Astronaut. 2015, 116, 117-125. [CrossRef]

35. Fazzolari, F.A. Generalized exponential, polynomial and trigonometric theories for vibration and stability analysis of porous FG sandwich beams resting on elastic foundations. Compos. Part B Eng. 2017, in press. [CrossRef]

36. Reddy, J.N. Mechanics of Laminated Composite Plates and Shells: Theory and Analysis, 2nd ed.; CRC Press: Boca Raton, FL, USA, 2004.

37. Leissa, A.W. Vibration of Shells; Acoustical Society of America: New York, NY, USA, 1993.

38. Tornabene, F.; Fantuzzi, N. Mechanics of Laminated Composite Doubly-Curved Shell Structures; Esculapio: Bologna, Italy, 2014.

39. Tornabene, F.; Bacciocchi, M.; Fantuzzi, N.; Reddy, J.N. Multiscale Approach for Three-Phase CNT/Polymer/Fiber Laminated Nanocomposite Structures. Polym. Compos. 2017, in press. [CrossRef] 